\title{
QUALITY OF LIFE IN PATIENTS WITH DIABETES MELLITUS
}

\author{
Naima Ahmed ${ }^{1}$, Nehlin Tomalika ${ }^{1}$, Mir Masudur Rhaman ${ }^{1}$, \\ Hasina Momtaz ${ }^{1}$, Md. Mahmudul Haque ${ }^{2}$
}

\begin{abstract}
${ }^{1}$ Department of Community Medicine, Ibrahim Medical College, 122, Kazi Nazrul Islam Avenue, Shahbagh, Dhaka-1000, Bangladesh; ${ }^{2}$ Department of Community Medicine, National Institute of Preventive and Social Medicine, Mohakhali, Dhaka, Bangladesh
\end{abstract}

\begin{abstract}
Background and objectives: Diabetes mellitus (DM) perpetually affects the quality of life. This non-communicable lifelong disease usually develops micro and macro-vascular complications affecting vital organs. Thus, it reduces the functional capability of health as assessed by the health-related quality of life (HRQOL) measuring tools. It is not known, how much HRQOL of the diabetic population in Bangladesh is affected.

Therefore, the objective of the present study was to estimate the levels of HRQOL of cases with DM attending a tertiary care hospital in Dhaka city. The study considered socioeconomic condition, nutritional status, duration of diabetes and treatment modalities while analyzing the HRQOL.

Methods: This study was conducted in a tertiary care hospital in Dhaka city from July 2016 to June 2017. Patients with DM were considered eligible and were recruited. Those who were found to have complications like retinopathy, nephropathy, neuropathy, hypertension and stroke were excluded based on previous investigations. Once selected, the study protocol was described to each of the diabetic patients. If agreed, the participant was interviewed. Short Form health survey questionnaire (SF-36) was used for assessment of HRQOL. The assessment of physical health components included physical function, role physical, body pain, and general health. Mental health components were emotion, vitality and social function.

Results: A total of 150 diabetic patients (m/f: 80/70) were included in the study. Comparisons of demographic variables between male and female participants showed no significant difference. As regards HRQOL, physical function score was significantly reduced among those who had diabetes for more than 10 years $(p=0.049)$. General health component was significantly impaired among those who had higher BMI $\left(<30 \mathrm{~kg} / \mathrm{m}^{2} ; p=0.016\right)$ and postprandial hyperglycemia. Longer duration of DM $(>10 \mathrm{yrs})$ and higher BMI significantly reduced components of mental health quality.
\end{abstract}

Conclusion: The study revealed that the overall physical and mental quality of life was significantly affected by longer duration of diabetes, obesity and glycemic status.

IMC J Med Sci 2018; 12(2): 73-79. EPub date: 31 December 2018

\section{Introduction}

The worldwide estimated prevalence of diabetes has been reported to increase from $4.3 \%$ in 1980 to
$9.0 \%$ in 2014 [1]. More than 2 million deaths every year is attributed to diabetes and its associated macro and microvascular complications and are the

\section{Address for Correspondence:}

Dr. Naima Ahmed, Lecturer, Department of Community Medicine, Ibrahim Medical College, 122, Kazi Nazrul Islam Avenue, Shahbagh, Dhaka-1000, Bangladesh,E-mail:drnaima1911@gmail.com 
seventh leading cause of chronic morbidity worldwide [2,3]. Based on the number of people with diabetes in 2014, the direct cost of diabetes is around US\$ 825 billion [4]. In Bangladesh, it is estimated that about $10 \%$ of population (8.4 million) above the age of 35 years have diabetes [5]. The annual per capita cost of diabetes care in Bangladesh has been reported to be US\$ 314 to US\$ $635[6,7]$.

In addition to other complications of diabetes, it also affects quality of life in terms of physical and mental health [8]. It also affects psychological state, level of independence, social relationships, personal beliefs and their relationship with others [9]. Lifelong medical treatment in diabetes may be taxing and reduce quality of life [10]. Physical activity and socio-economic factors largely influence the success of diabetes control. A meta-analysis which included 20 studies has confirmed that physically active individuals with diabetes maintains improved quality of life [11].

It was observed that education, self-management and psychological interventions helped to retard deterioration of quality of life in patients with diabetes [12]. The quality of life is based on an individual's perception of life in the context of the culture and value systems in which one lives and in relation to goals, expectations, standards and concerns [13].

Therefore, evaluation of quality of life can help planning of educational programs and intervention strategies. In Bangladesh, no study has yet been carried out on the status of health related quality of life of patients with diabetes. Therefore, the present study was undertaken to determine the HRQOL in patients with DM.

\section{Materials and Methods}

This cross-sectional study was carried out on diabetic patients attending a tertiary care hospital of Dhaka city from July 2016 to June 2017. Each patient was informed about the study for assessing health-related quality of life and was requested to participate. Anyone, who agreed to volunteer this study, was enlisted. Each enlisted participant was interviewed about his/her socio-demographic status and clinical history related to DM (time of diagnosis, duration and complications).
SF-36 questionnaire [14] was used to assess the quality of life. SF-36 was translated into Bengali language from its original version and was validated after a pilot interview. Questionnaire was filled by face-to-face interview. The SF-36 scale encompasses eight dimensions namely, 1) Physical functioning: assess the magnitude of physical quality of life like running, lifting heavy objects, participating in strenuous sports, moving a table, climbing several flights of stairs, bending, kneeling, walking more than a mile, bathing or dressing by themselves; 2) Social functioning: maintaining relations with family members, friends, neighbors and others; 3) Bodily pain: assess how much body pain hampers their enactment of daily activities, work-related duties in public domain and household job; 4) Role physical: limitations caused by physical health problems; 5) Role emotion (RE): limitations caused by emotional problems; 6) Mental health: emotional well-being score is related to one's inter alia feeling - full of energy, happy, feeling calm and peaceful, very nervous or feeling worn out and tired; 7) Vitality: the score is related to feeling energetic and full of liveliness, or worn out and tired; and 8) Perceptions of general health $(\mathrm{GH})$ : measures concepts such as excellent, very good, good, fair or poor, getting ill easier/earlier than other people perform. Each domain was transformed to a scale of 0-100 with zero indicating the worst health status and 100 the best. These dimensions evaluate the degree of individual's health related quality of life.

Quantitative variables were expressed in mean with standard deviation (SD) and comparisons between men and women were done by student's t test. Qualitative data were analyzed by Chi square or Z test. Different components of quality of life related to BMI, treatment modalities, duration of diabetes, etc were analyzed by ANOVA.

\section{Results}

A total of 150 diabetic patients (m/f: 80/70) agreed to participate in the study. The socio-demographic and clinical characteristics of all participants are shown in Table-1 and Table-2. The mean age of all participants was $52.8 \pm 6.9$ years and the mean BMI was $25.8 \pm 3.3 \mathrm{~kg} / \mathrm{m}^{2}$. Except BMI, no significant difference was observed between male and female cases with regard to diet, exercise, duration of diabetes, glycemic status, use of oral hypoglycemic agents or insulin (Table-1 and 2). 
Table-1: Socio-demographic and clinical status of study population

\begin{tabular}{lcccc}
\hline \multirow{2}{*}{ Variables } & Total & Male $(\mathbf{n}=\mathbf{8 0})$ & Female $(\mathbf{n}=\mathbf{7 0})$ & \multirow{2}{*}{$p$} \\
\cline { 2 - 4 } & Mean \pm SD & Mean \pm SD & Mean \pm SD & \\
\hline Age (y) & $52.8 \pm 6.9$ & $55.0 \pm 6.6$ & $50.2 \pm 6.3$ & 0.68 \\
Weight $(\mathrm{Kg})$ & $65.6 \pm 10.3$ & $68.7 \pm 9.7$ & $62.2 \pm 9.9$ & 0.87 \\
Height $(\mathrm{cm})$ & $159.4 \pm 8.6$ & $164.7 \pm 7.0$ & $153.3 \pm 5.9$ & 0.14 \\
Body Mass Index $\left(\mathrm{kg} / \mathrm{m}^{2}\right)$ & $25.8 \pm 3.3$ & $25.3 \pm 3.0$ & $26.3 \pm 3.5$ & $0.03 *$ \\
Fasting blood glucose (mmol/L) & $8.6 \pm 3.6$ & $8.4 \pm 3.2$ & $8.9 \pm 4.0$ & 0.28 \\
Post Prandial glucose (mmol/L) & $11.5 \pm 4.3$ & $11.4 \pm 3.4$ & $11.5 \pm 5.1$ & 0.14 \\
Income (In Taka) & $33262 \pm 22126$ & $34342 \pm 24534$ & $32028 \pm 19108$ & 0.52 \\
\hline
\end{tabular}

Note: $a=$ based on expenditure; *indicates significant following unpaired $t$-tests; $S D=$ standard deviation

Detail scores of physical and mental dimensions of HRQOL are shown in Table-4 and 5. The overall scores of different physical dimensions were found reduced in patients with DM. Physical function score was significantly $(p=0.04)$ reduced among those who had history of diabetes for more than 10 years compared to those with lesser durations. General health score was significantly impaired among those who had BMI of more than $30 \mathrm{~kg} / \mathrm{m}^{2}$ $(p=0.01)$ and post-prandial hyperglycemia of $>13.1$ $\mathrm{mmol} / \mathrm{l}(p<0.01)$. For mental health component, patients with history of longer duration $(>10 \mathrm{yrs})$ of DM had significantly reduced role emotion score $(p<0.01)$ compared to other groups. None of the mental dimension components was affected by the treatment modalities. Vitality score was found significantly $(p=0.02)$ reduced among those who had FBG level between 7.6-9.6 mmol/1 compared to those with other glycemic levels. Significantly reduced mental health score was found among cases with 3-6 yrs of duration of diabetes $(p=0.01)$. Higher obesity $\left(>30 \mathrm{~kg} / \mathrm{m}^{2}\right)$ also revealed significantly reduced quality of mental health score $(p<0.01)$. Cases with increased post-prandial hyperglycemia $(\geq 13.1 \mathrm{mmol} / \mathrm{l})$ also had significantly reduced quality of social function $(p<0.01)$.
Table-2: Duration of diabetes mellitus and treatment category of study population

\begin{tabular}{cccc}
\hline Variables & $\begin{array}{c}\text { Total } \\
\text { case } \\
(\mathbf{n = 1 5 0 )}\end{array}$ & $\begin{array}{c}\text { Male } \\
(\mathbf{n}=\mathbf{8 0})\end{array}$ & $\begin{array}{c}\text { Female } \\
(\mathbf{n}=\mathbf{7 0})\end{array}$ \\
\cline { 2 - 4 } & $\mathbf{n}(\%)$ & $\mathbf{n ~ ( \% )}$ & $\mathbf{n ~ ( \% )}$ \\
\hline $\begin{array}{c}\text { Duration of DM (year) } \\
<3\end{array}$ & 29 & 16 & 13 \\
& $(19.3)$ & $(20.0)$ & $(18.5)$ \\
$3-6$ & 42 & 20 & 22 \\
& $(28.0)$ & $(25.0)$ & $(31.4)$ \\
$6-10$ & 39 & 23 & 16 \\
& $(26.0)$ & $(28.7)$ & $(22.8)$ \\
$>10$ & 40 & 21 & 19 \\
& $(26.7)$ & $(26.2)$ & $(27.1)$
\end{tabular}

\begin{tabular}{|c|c|c|c|}
\hline \multicolumn{4}{|l|}{ Treatment category } \\
\hline $\begin{array}{l}\text { Diet and physical } \\
\text { exercise }\end{array}$ & $\begin{array}{c}23 \\
(15.3)\end{array}$ & $\begin{array}{c}14 \\
(17.5)\end{array}$ & $\begin{array}{c}9 \\
(12.8)\end{array}$ \\
\hline $\begin{array}{l}\text { Oral hypoglycemic } \\
\text { drugs }\end{array}$ & $\begin{array}{c}86 \\
(57.3)\end{array}$ & $\begin{array}{c}45 \\
(56.2)\end{array}$ & $\begin{array}{c}41 \\
(58.6)\end{array}$ \\
\hline Insulin & $\begin{array}{c}16 \\
(10.6)\end{array}$ & $\begin{array}{c}6 \\
(7.5)\end{array}$ & $\begin{array}{c}10 \\
(14.3)\end{array}$ \\
\hline $\begin{array}{l}\text { Insulin+oral } \\
\text { hypoglycemic drugs }\end{array}$ & $\begin{array}{c}25 \\
(16.6)\end{array}$ & $\begin{array}{c}15 \\
(18.7)\end{array}$ & $\begin{array}{c}10 \\
(14.3)\end{array}$ \\
\hline
\end{tabular}


Ahmed N et al.

IMC J Med Sci 2018; 12(2): 73-79

76

Table-3: Condition of Physical health components of HRQOL in relation to clinical and biochemical status of the study population

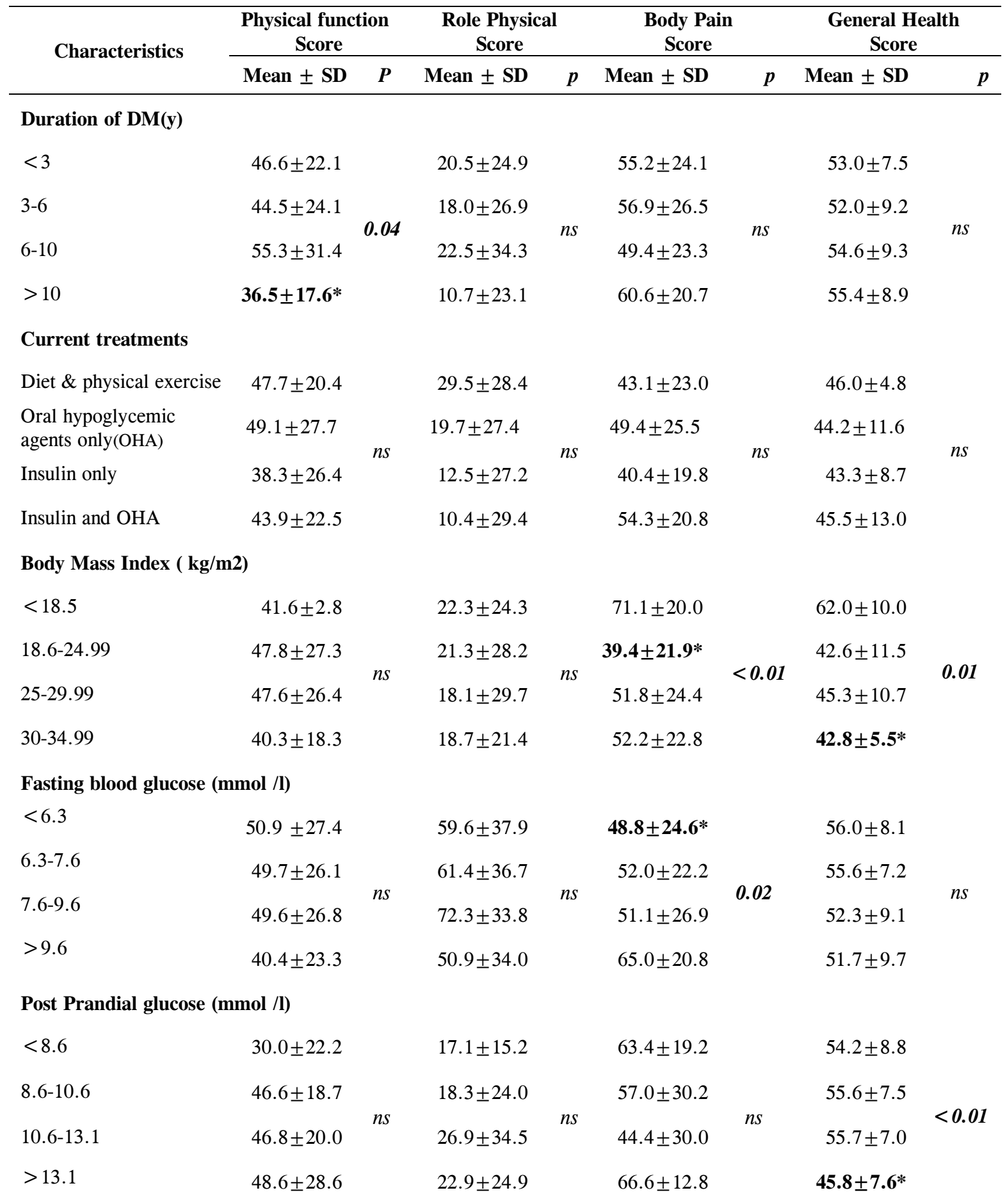

Note: *indicates significant compared to highest mean score by ANOVA and Duncan's multiple range test; $n s=n o t$ significant $(p>0.05)$. 
Table-4: Condition of mental health components of HRQOL in relation to clinical and biochemical status of study population

\begin{tabular}{|c|c|c|c|c|c|c|c|c|}
\hline \multirow[t]{2}{*}{ Characteristics } & \multicolumn{2}{|c|}{$\begin{array}{c}\text { Role Emotion } \\
\text { Score }\end{array}$} & \multicolumn{2}{|l|}{$\begin{array}{c}\text { Vitality } \\
\text { Score }\end{array}$} & \multicolumn{2}{|c|}{$\begin{array}{c}\text { Mental Health } \\
\text { Score }\end{array}$} & \multicolumn{2}{|c|}{$\begin{array}{c}\text { Social Function } \\
\text { Score }\end{array}$} \\
\hline & Mean \pm SD & $p$ & Mean \pm SD & $p$ & Mean \pm SD & $p$ & Mean \pm SD & $P$ \\
\hline \multicolumn{9}{|l|}{ Duration of DM (yrs) } \\
\hline$<3$ & $65.5 \pm 28.8$ & \multirow{4}{*}{$<0.01$} & $50.0 \pm 9.0$ & \multirow{4}{*}{$\begin{array}{c}0.01 \\
0.03 \& \\
<0.05\end{array}$} & $51.0 \pm 12.7$ & & $54.3 \pm 15.0$ & \multirow{4}{*}{$n s$} \\
\hline $3-6$ & $77.9 \pm 36.8$ & & $38.4 \pm 13.6^{* b}$ & & $37.2 \pm 17.9 *$ & \multirow{3}{*}{$<0.01$} & $47.9 \pm 16.0$ & \\
\hline $6-10$ & $81.1 \pm 28.4$ & & $45.5 \pm 11.1$ & & $49.6 \pm 12.8$ & & $51.9 \pm 18.9$ & \\
\hline$>10$ & $44.1 \pm 38.0^{* a}$ & & $44.8 \pm 10.4$ & & $45.4 \pm 11.9$ & & $56.2 \pm 2.4$ & \\
\hline \multicolumn{9}{|l|}{ Current treatments } \\
\hline Diet \& physical exercise & $66.6 \pm 30.8$ & \multirow{4}{*}{$n s$} & $48.6 \pm 9.8$ & \multirow{4}{*}{$n s$} & $46.8 \pm 12.7$ & \multirow{4}{*}{$n s$} & $55.6 \pm 8.3$ & \multirow{4}{*}{$n s$} \\
\hline Oral hypoglycemic drug & $67.4 \pm 35.0$ & & $42.8 \pm 12.7$ & & $45.8 \pm 17.2$ & & $51.7 \pm 17.9$ & \\
\hline Insulin & $47.9 \pm 43.8$ & & $47.66 \pm 8.83$ & & $46.2 \pm 11.8$ & & $57.8 \pm 20.8$ & \\
\hline $\begin{array}{l}\text { Insulin and Oral } \\
\text { hypoglycemic drug }\end{array}$ & $48.0 \pm 34.8$ & & $44.3 \pm 11.2$ & & $40.9 \pm 9.6$ & & $48.5 \pm 15.0$ & \\
\hline \multicolumn{9}{|l|}{ Body Mass Index ( kg/m2) } \\
\hline$<18.5$ & $66.6 \pm 0.0$ & \multirow{4}{*}{ ns } & $30.0 \pm 0.0$ & \multirow{4}{*}{$n s$} & $38.0 \pm 10.0$ & \multirow{4}{*}{$<0.01$} & $37.5 \pm 0.0$ & \multirow{4}{*}{$n s$} \\
\hline $18.5-24.99$ & $54.8 \pm 39.7$ & & $46.4 \pm 10.3$ & & $50.2 \pm 11.6$ & & $54.9 \pm 15.8$ & \\
\hline $25-29.99$ & $67.0 \pm 34.3$ & & $44.1 \pm 11.9$ & & $45.1 \pm 15.0$ & & $51.8 \pm 17.2$ & \\
\hline $30-34.99$ & $54.1 \pm 34.1$ & & $40.7 \pm 15.7$ & & $34.7 \pm 18.4^{*}$ & & $50.7 \pm 17.3$ & \\
\hline \multicolumn{9}{|c|}{ Fasting blood glucose (mmol /l) } \\
\hline$<6.3$ & $21.2 \pm 29.3$ & \multirow{4}{*}{$n s$} & $50.0 \pm 12.0$ & \multirow{4}{*}{0.02} & $46.4 \pm 13.6$ & & $57.5 \pm 13.2$ & \multirow{4}{*}{$n s$} \\
\hline $6.3-7.6$ & $18.2 \pm 30.4$ & & $44.4 \pm 12.0$ & & $46.8 \pm 14.6$ & \multirow{3}{*}{$n s$} & $51.9 \pm 17.0$ & \\
\hline 7.6-9.6 & $15.7 \pm 29.7$ & & $41.2 \pm 11.9^{*}$ & & $43.2 \pm 18.8$ & & $49.6 \pm 20.2$ & \\
\hline$>9.6$ & $19.5 \pm 24.3$ & & $42.5 \pm 10.9$ & & $45.0 \pm 13.7$ & & $50.3 \pm 16.1$ & \\
\hline \multicolumn{9}{|c|}{ Post Prandial glucose (mmol /l) } \\
\hline$<8.6$ & $57.1 \pm 35.6$ & \multirow{4}{*}{$n s$} & $43.8 \pm 15.4$ & \multirow{4}{*}{$n s$} & $42.8 \pm 14.6$ & & $57.1 \pm 11.7$ & \multirow{4}{*}{$<0.01$} \\
\hline $8.6-10.6$ & $53.3 \pm 43.2$ & & $43.2 \pm 9.9$ & & $41.0 \pm 16.6$ & $n_{S}$ & $59.1 \pm 18.5$ & \\
\hline $10.6-13.1$ & $57.1 \pm 21.6$ & & $41.2 \pm 12.4$ & & $48.6 \pm 18.6$ & $n s$ & $36.5 \pm 16.5^{*}$ & \\
\hline$>13.1$ & $58.9 \pm 30.8$ & & $43.0 \pm 8.0$ & & $50.7 \pm 11.0$ & & $49.0 \pm 13.9$ & \\
\hline
\end{tabular}

Note: * indicates significant compared to highest mean score by ANOVA and Duncan's multiple range test; $a=$ participants having DM for $>10$ years duration had significantly reduced score compared to others; $b=$ participants having DM for 3-6 years duration had significantly reduced score compared to others. $n s=$ not significant $(p>0.05)$.

\section{Discussion}

In the present study, we have observed the overall scores of different components of both physical and mental dimensions of HRQOL were low in our study population. The mean scores of all components were around half of the highest scores of the scale. It was found that the longer duration of DM and higher BMI were the most important factors affecting negatively the quality of life. The quality of life in all areas was comparatively better when the duration of diabetes was less than 3 years. A study in Iran reported significant negative linear correlations between duration of disease and mean scores of all scales of HRQOL except physical functioning [15]. 
In the present study, there was no effect of use of insulin on any components of physical and mental health dimensions. However, Johnson et al [16] reported that insulin use in DM was related to worse HRQOL in terms of role-physical, general health, and social functioning. While Wexler et al [17] did not observe any relationship between treatment regimens in patients with DM and HRQOL.

The study findings revealed that obese diabetic patients had a lower score of mental health compared to those having lower BMI. Similarly, general health scores were also lower in diabetic obese cases compared to other groups. Sepúlveda, et al, reported that obese patients had worse physical functioning than normal and overweight patients, and also worse vitality than their normal weight counterparts [18]. However, in the present study we observed lower body pain scores in normal weight than overweight patients.

The current study showed a significantly better score in social function, general health and vitality components among the patients having better glycemic control. However, no significant positive or negative effect of glycemic status was observed on other physical and mental health components of HRQOL.

The present study has demonstrated that DM adversely affects different aspects of the HRQOL. The overall scores of physical and mental health dimensions are reduced and the most important influencing factors are BMI and duration of diabetes.

\section{Acknowledgements}

We are very grateful to the National Institute of Preventive \& Social Medicine (NIPSOM), Bangabandhu Sheikh Mujib Medical University (BSMMU) and Ibrahim Medical College (IMC) for giving us active cooperation to complete the study. We are also grateful to Professor MA Sayeed, Professor J. Ashraful Haq, Dr. Masuda Mohsena and all colleagues of the Department of Community Medicine, Ibrahim Medical College for their valuable suggestions.

\section{Author's contributions}

NA was involved in project management \& supervision and in maintenance of contact with
BSMMU. NT was involved in data analysis and manuscript writing. MMR was involved in selection of participants, data analysis and manuscript writing. HM was involved in manuscript writing. MMH was involved in overall supervision of the study.

Competing interest: Authors declare no conflict of interest.

\section{Ethics approval and consent to participate and publish}

This study was approved by the Ethical Committee of the National Institute of Preventive and Social Medicine. Written consent was collected from every participant for publication.

\section{Funding: None}

\section{References}

1. Worldwide trends in diabetes since 1980: a pooled analysis of 751 population-based studies with 4.4 million participants. The Lancet. 2016; 387(10027): 1513-1530.

2. Global Burden of Metabolic Risk Factors for Chronic Diseases Collaboration. Cardiovascular disease, chronic kidney disease, and diabetes mortality burden of cardiometabolic risk factors from 1980 to 2010: a comparative risk assessment. Lancet Diabetes Endocrinol. 2014; 2: 634-47.

3. Global Burden of Disease Study Collaborators. Global, regional, and national incidence, prevalence, and years lived with disability for 301 acute and chronic diseases and injuries in 188 countries, 1990-2013: a systematic analysis for the Global Burden of Disease Study 2013. The Lancet. 2015; 386: 743-800.

4. Seuring T, Archangelidi O, Suhrcke M. The economic costs of type 2 diabetes: a global systematic review. Pharmacoeconomics. 2015; 33: 811-31.

5. Akhter S, Rahman MM, Abe SK, Sultana P. Prevalence of diabetes and prediabetes and their risk factors among Bangladeshi adults: a nationwide survey. Bull World Health Organ. 2014; 92: 204-213 A. doi: dx.doi.org/10.2471/BLT.13.12871. 
6. Afroz A, Habib SH, Chowdhury HA, Paul D, Shahjahan M, Hafez MA, et al. Healthcare cost of type 2 diabetes mellitus in Bangladesh: a hospital-based study. Int $J$ Diabetes Dev Ctries. 2016: 36(2): 235-241.

7. Islam SMS, Lechner A, Ferrari U, Laxy M, Seissler J, Brown J, et al. Healthcare use and expenditure for diabetes in Bangladesh.BMJ Global Health. 2017; 2:e000033. doi:10.1136/bmjgh-2016- 000033

8. Wang HF, Yeh MC. The quality of life of adults with type 2 diabetes in a hospital care clinic in Taiwan Qual Life Res. 2013; 22(3): 577-584.

9. Skevington SM, Lofty M, O'Connell KA. The World Health Organization's WHOQOL-BREF quality of life assessment: psychometric properties and results of the international field trial. A report from the WHOQOL group. Qual Life Res. 2004; 13(2): 299-310. doi.org/10.1023/B:QURE.0000018486.91360.00

10. Jacobson AM, de Groot M, Samson JA. The evaluation of two measures of quality of life in patients with type I and type II diabetes. Diabetes Care. 1994; 17(4): 267-274.

11. Cochran J, Conn VS. Meta-analysis of quality of life outcomes following diabetes selfmanagement training. Diabetes Educ. 2008; 34(5):815-823. doi.org/10.1177/0145721708323640.
12. Steed L, Cooke D, Newman S. A systematic review of psychosocial outcomes following education, self-management and psychological interventions in diabetes mellitus. Patient Educ Couns. 2003; 51(1): 5-15.

13. The WHO quality of life assessment (WHOQOL) development and general psychometric properties. Soc Sci Med. 1998; 46(12): 1569-1585.

14. Ware JE. SF-36 Health Survey. Manual and Interpretation guide. The Health Institute, New England Medical Center: Boston, MA, 1992.

15. Hadi, N, Ghahramani S, Montazeri A. Health related quality of life in both types of diabetes in Shiraz, Iran. Shiraz E-Medl J. 2013; 14(2): $112-122$

16. Johnson JA, Nowatzki TE, Coons SJ. Healthrelated quality of life of diabetic Pima Indians.Med Care. 1996; 34(2): 97-102.

17. Wexler DJ, Grant RW, Wittenberg E, Bosch JL, Cagliero E, Delahanty L, et al. Correlates of health-related quality of life in type-2 diabetes. Diabetologia. 2006; 49(7): 14891497.

18. Sepúlveda E, Poínhos R, Constante M, PaisRibeiro J, Freitas P, Carvalho D. Healthrelated quality of life in type 1 and type 2 diabetic patients in a Portuguese central public hospital. Diab Metab SyndrObes: Targets and Therapy. 2015; 8: 219-226. 